\title{
Review Article \\ Role of MicroRNA-1 in Human Cancer and Its Therapeutic Potentials
}

\author{
Chao Han, ${ }^{1}$ Zujiang Yu, ${ }^{1}$ Zhenfeng Duan, ${ }^{2}$ and Quancheng Kan ${ }^{1}$ \\ ${ }^{1}$ Department of Clinical Pharmacology, The First Affiliated Hospital of Zhengzhou University, Zhengzhou 450052, China \\ ${ }^{2}$ Sarcoma Biology Laboratory, Center for Sarcoma and Connective Tissue Oncology, \\ Massachusetts General Hospital, Boston, MA 02114, USA
}

Correspondence should be addressed to Quancheng Kan; quanchengkan@yeah.net

Received 12 November 2013; Revised 19 February 2014; Accepted 23 February 2014; Published 18 May 2014

Academic Editor: Hesham H. Ali

Copyright (C) 2014 Chao Han et al. This is an open access article distributed under the Creative Commons Attribution License, which permits unrestricted use, distribution, and reproduction in any medium, provided the original work is properly cited.

\begin{abstract}
While the mechanisms of human cancer development are not fully understood, evidence of microRNA (miRNA, miR) dysregulation has been reported in many human diseases, including cancer. miRs are small noncoding RNA molecules that regulate posttranscriptional gene expression by binding to complementary sequences in the specific region of gene mRNAs, resulting in downregulation of gene expression. Not only are certain miRs consistently dysregulated across many cancers, but they also play critical roles in many aspects of cell growth, proliferation, metastasis, apoptosis, and drug resistance. Recent studies from our group and others revealed that miR-1 is frequently downregulated in various types of cancer. Through targeting multiple oncogenes and oncogenic pathways, miR-1 has been demonstrated to be a tumor suppressor gene that represses cancer cell proliferation and metastasis and promotes apoptosis by ectopic expression. In this review, we highlight recent findings on the aberrant expression and functional significance of miR-1 in human cancers and emphasize its significant values for therapeutic potentials.
\end{abstract}

\section{Introduction}

MicroRNAs (miRNAs, miRs) are a subset of small noncoding RNA molecules that are approximately 22 base pairs in length. miRs play important roles in many aspects of cell biology, including cell fate determination, metabolism, stress responses, apoptosis, and carcinogenesis [1-4]. miRs were first discovered in 1993 during a study of Caenorhabditis elegans development, associated with the gene lin-14 [5]. The evolution of most miRs is very conservative and often found in clusters [6]. Primary miRs are produced by RNA polymerase II (Pol II) in a stem-loop structurez and then cropped to form precursor miR (pre-miR) hairpins in the nucleus and cytoplasm by a multiprotein complex that includes Drosha and Dicer. Finally, the pre-miRs are cleaved by Dicer to produce mature miRs [7-9]. Mature miRs mainly bind to the $3^{\prime}$-untranslated regions (UTRs) of target genes and inhibit gene expression by degradation or repress translation of the target mRNA (Figure 1) [10, 11]. So far, more than 2,500 human miRs have been registered at miRBase in release 20.0 (http://microrna.sanger.ac.uk/). Bioinformatics predictions indicate that miRs regulate more than $60 \%$ of protein-coding genes [10].

Recently, the function of miRs in human cancers has been of interest to many [12-14]. Numerous studies have demonstrated dysregulation of miRs in tumors by microarray assay $[15,16]$. The aberrant expression of miRs is mainly divided into two classes: upregulated miRs and downregulated miRs. Low expression of miRs in cancer has been reported to repress or downregulate the expression of oncogenes, resulting in the inhibition of cancer cell proliferation [17, 18]. Other highly expressed miRs in cancer have been shown to inhibit tumor suppressor genes and promote tumor proliferation and metastasis $[19,20]$. Although specific miRs are overexpressed in cancer cells, most are downregulated in tumors, thus suggesting the possibility of more tumor suppressing miRs than oncogenic miRs $[21,22]$. Among them, miR-1 is the most consistently decreased miR in various human cancers, suggesting the great potential miR-1 replacement therapy holds for cancer treatment. 


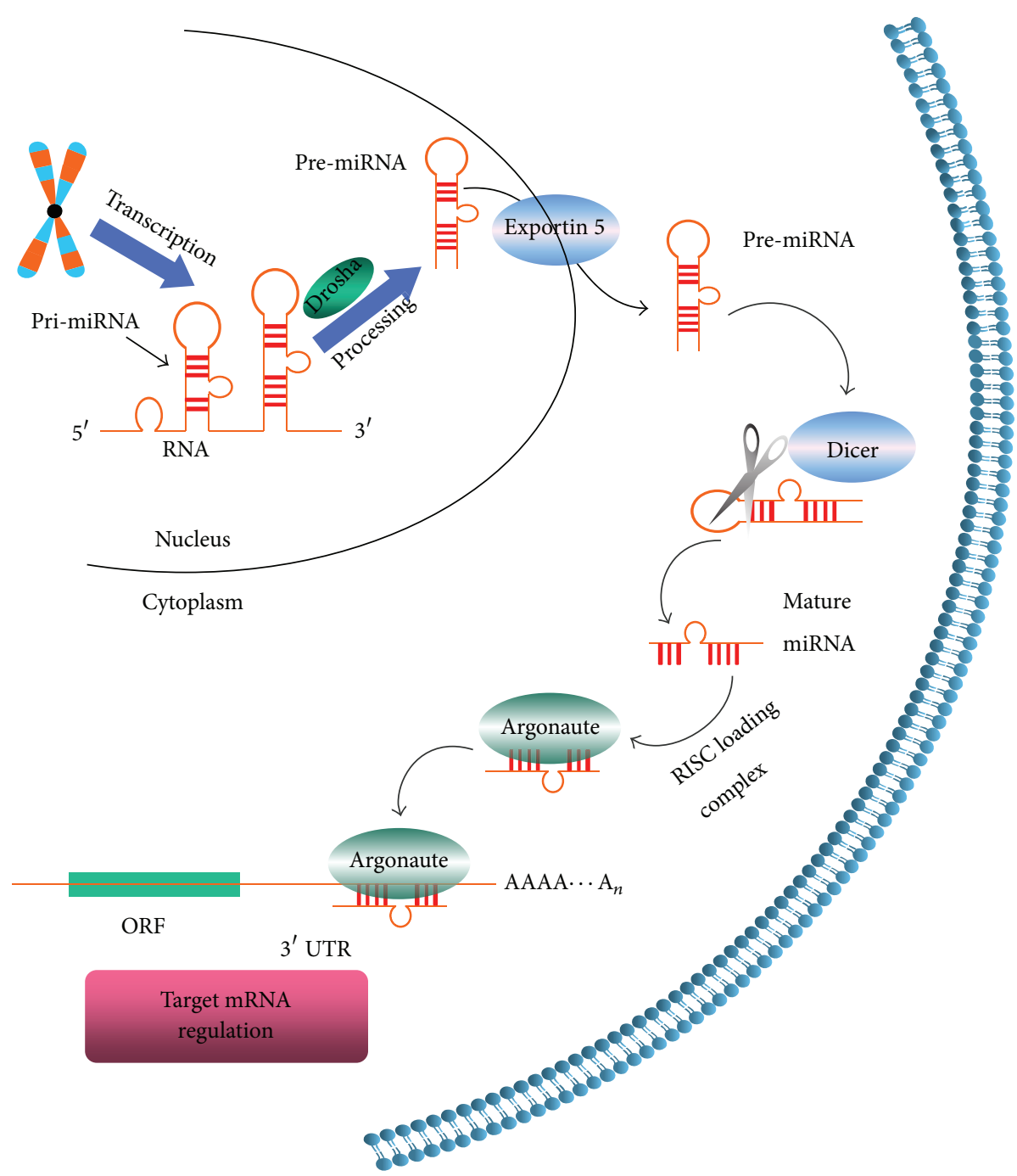

FIgURE 1: Biological principles of miRNA (miR). miR genes are transcribed by RNA polymerase II (Pol II) to generate the primary transcripts (pri-miRNAs). The following step is mediated by the Drosha complex that generates $\sim 65$ nucleotide (nt) precursor-miRs (pre-miRNAs). PremiR has a short stem plus a $\sim 2$-nt $3^{\prime}$ overhang, which is recognized by the nuclear export factor exportin 5 . On export from the nucleus, the cytoplasmic RNase III Dicer catalyzes the second processing (dicing) step to produce miR duplexes. One strand of the duplex pre-miR remains as the mature miR, whereas the other strand is degraded. Dicer and Argonaute mediate the processing of pre-miR and the miR mature strand is then assembled into the RNA-induced silencing complex (RISC) and targets the complementary mRNA $3^{\prime}$-UTR sequences via translational repression or mRNA cleavage.

\section{Basic Biology of miR-1 and Validated Functions of miR-1 in Normal Tissues}

There are two different precursors of miR-1 in human, miRNA-1-1 and miRNA-1-2, both of which are processed into an identical mature form of miR-1. miRNA-1-1 and miRNA-12 are located in two distinct chromosomal regions in human genome, $-20 \mathrm{q} 13.33$ and 18q11.2, respectively (Figure 2). Inside the cell, miR-1 is transcribed as $\sim 70$ nucleotide precursors and subsequently processed by the Dicer enzyme to give $\sim 22$ nucleotide mature products. The mature sequence comes from the $3^{\prime}$ arm of the miR-1 precursor. Literature review suggests miR-1 to be expressed specifically in the normal cardiac and skeletal muscle tissues. Upon induction of myogenic differentiation, miR-1 was highly expressed. Retrovirus-mediated overexpression of miR-1 markedly enhanced expression of muscle creatine kinase, sarcomeric myosin, and alpha-actinin, while the effects on myogenin and MyoD expression were modest. Formation of myotubes was significantly augmented in miR1-overexpressing cells, indicating that miR-1 expression enhanced both myogenic differentiation and maturation into myotubes [23]. A more recent study showed that miR-1 induction can directly downregulate Notch3 and allow differentiation of myoblast cells [24], suggesting that myogenic differentiation-induced miR-1 is critical for differentiation at least partly by turning off Notch 3 . Notch 3 serves as a regulator for preventing premature myogenic differentiation [24]. 


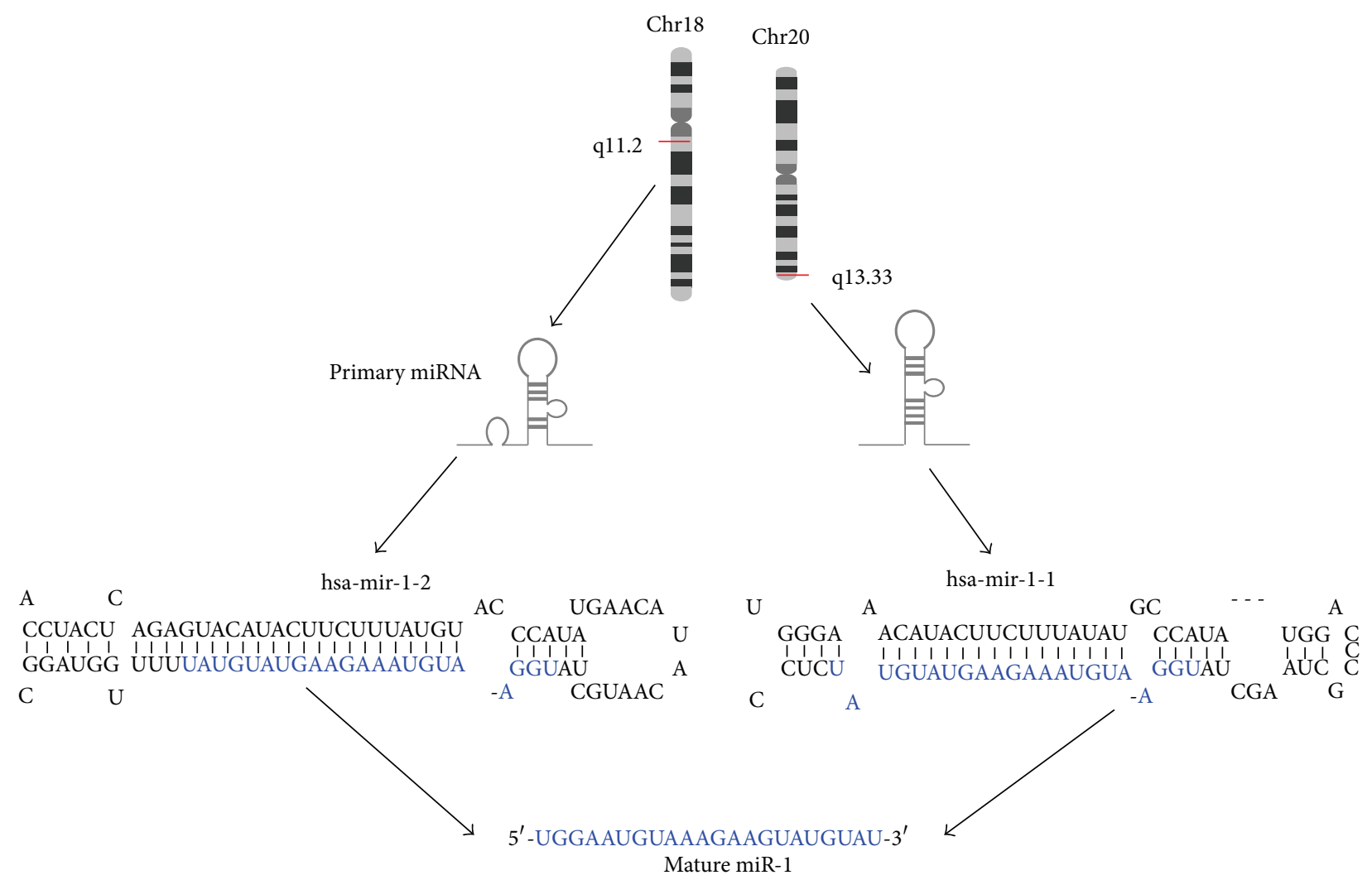

Figure 2: Alignment of two different precursors (hsa-miR-1-1 and hsa-miR-1-2) of miR-1 in human. hsa-miR-1-1 and hsa-miR-1-2 are located in two distinct chromosomal regions in human genome, $-20 \mathrm{q} 13.33$ and 18q11.2. Both these precursors are processed into an identical mature form of miR-1. The respective pre-miR-1 sequences (hsa-miR-1-1 and hsa-miR-1-2) were listed. Each sequence is shown with blue characters indicating mature miR-1 nucleotides.

\section{Expression of miR-1 in Noncancer Human Diseases}

miR-1 has crucial functions in the development and physiology of muscle tissues and related diseases $[25,26]$. Studies have shown abnormal miR-1 expression in heart diseases including myocardial infarction, arrhythmias, and heart failure [27-29]. Reduction in expression of miR-1 has been found in serum of patients with chronic obstructive pulmonary disease (COPD), and miR-1 is downregulated in myocardial infracted tissue [30]. Expression of miR-1 was associated with smoking history and lung function. Furthermore, the protein levels of histone deacetylase 4 (HDAC4), a miR-1 target gene, were increased in the patients with COPD. miR-1 expression was negatively correlated with phosphorylation of the Akt kinase [31]. These data suggest that expression of miR-1 may contribute to COPD-associated skeletal muscle dysfunction.

\section{Aberrant Expression of miR-1 in Human Cancers}

Using high-throughput miR microarray technology and quantitative RT-PCR (qRT-PCR) for validation, many studies have found decreased expression of miR-1 in various types of human cancers (Table 1). Associations between miR-1 expression levels and tumor type, grade, response to treatment, and prognosis have also been reported in recent studies. We will review the expression of miR-1 and its potential functions in lung cancer, gastrointestinal cancer, genitourinary cancer, head and neck cancer, and sarcoma.

4.1. miR-1 in Lung Cancer. Lung cancer is the leading cause of cancer-related deaths in men and women in the world [32]. miR-1 has been shown to be significantly downregulated in vinyl carbamate- (VC-) induced mouse lung tumor models [33]. miR-1 expression is not only significantly reduced in primary lung cancer tissues but also in many lung cancer cell lines [34-36]. miR-1 has been shown to be antitumorigenic in lung cancer cells $[34,36,37]$. Expression of miR-1 in non-miR expressing lung cancer cells reversed their tumorigenic properties of growth, replication potential, motility/migration, clonogenic survival, and tumor formation in nude mice [34]. Exogenous miR-1 significantly reduced expression of oncogenic targets, MET and Pim-1. MET and Pim-1 are frequently upregulated in lung cancer and promote the growth and survival of cancer cells. Similarly, the levels of two additional targets, FoxP1, a transcription factor with ontogenetic property, and HDAC4, that represses differentiation-promoting genes, were also reduced in miR1-expressing cells. Conversely, depletion of miR-1 increased cell growth with associated elevation of these target genes [34]. In a recent study of serum miR signature to predict 
TABLE 1: Altered expression of miR-1 in different cancers.

\begin{tabular}{|c|c|c|c|}
\hline Cancer type & miR-1 downregulation & miR-1 target genes & Reference number \\
\hline Lung cancer & Primary lung cancer tissue and serum & MET; FoxP1; HDAC4; Slug; PIK3CA & {$[33,36-38]$} \\
\hline Colon cancer & Different colon cancer tissues & MET & [43] \\
\hline Genitourinary cancer & Cancer cell lines and tissues & LASP1; TAGLN2; SRSF9; PTMA; PNP1 & {$[50,56,57]$} \\
\hline Head and neck cancer & Laryngeal carcinoma and MSSCC & TAGLN2; PTMA; FN1; PNP & {$[61,62]$} \\
\hline Thyroid cancer & Thyroid adenomas and carcinomas & CCND2; CXCR4; CXCL12 & {$[66]$} \\
\hline Hepatocellular cancer & HCC cell lines and tumor tissues & MET; FoxP1; HDAC4; ET-1 & [39-41] \\
\hline Sarcoma & Sarcoma cell lines and sarcoma tissues & MET; CCND2; HDAC4 & {$[68,69,73]$} \\
\hline
\end{tabular}

survival of non-small-cell lung cancer (NSCLC), miR-1 level in serum was found to be significantly lower in shortersurvival group as compared with longer-survival group, and levels of miR-1 were significantly associated with overall survival [38]. Meanwhile, one study about miR-1 and NSCLC found that almost $70 \%$ of the NSCLC tissue samples showed low miR-1 expression and high PIK3CA expression [35]. Moreover, there is a significant relationship between the expression levels of miR-1 and PIK3CA in NSCLC and clinical characteristics and prognosis [35]. The results show that not only the patients with low miR-1 expression but also those with high PIK3CA expression had significantly higher incidences of lymph node metastases and recurrences in one year after surgery than other patients. So, the expression levels of miR-1 and PIK3CA in NSCLC tissues may be useful for predicting lymph node metastasis and postoperative recurrence in patients with NSCLC [35]. In another study, lung cancer A549 cells overexpressing miR-1 exhibited a significant morphological change from a mesenchymal to an epithelial phenotype characterized by cell polarization and intercellular junctions [37]. The cells showed increased expression of E-cadherin, which colocalized with cortical actin filaments and vinculin to form typical adherens junctions at the apical regions of intercellular borders. Moreover, the cells migratory and invasive activities were decreased, and their sensitivity to doxorubicin was increased. Interestingly, the structural and tumorigenic properties induced by miR1 were associated with the reduced expression of Slug, which was a transcriptional repressor of E-cadherin or an inducer of epithelial-to-mesenchymal transition [37]. The E-cadherinactin filaments and vinculin complex play a crucial role in epithelial cell-cell adhesion and in the maintenance of tissue architecture [37]. The effect of overexpressing miR-1 on the E-cadherin-actin filaments and vinculin complex may reflect the underlying mechanisms of miR-1 on cell migration and invitation.

4.2. miR-1 in Gastrointestinal Cancer. Gastrointestinal carcinomas are common malignant diseases worldwide. Among them, hepatocellular carcinoma (HCC) is the fifth most prevalent cancer and is the third leading cause of cancerrelated death in China; colorectal cancer is the third most common cancer in the world, accounting for about $9 \%$ of all new cases of cancer. Gastrointestinal cancer carcinogenesis has been widely studied at the molecular level in recent years; however, the mechanism remains unclear. Recently, miR dysregulation has been described in different gastrointestinal cancers. miR-1 expression is significantly reduced in primary human hepatocellular carcinomas (HCCs) compared with matching normal liver tissues [39]. Ectopic expression of miR-1 in HCC cells inhibited cell growth and reduced replication potential and clonogenic survival [39-41]. FoxP1 and MET genes harbor three and two miR-1 binding sites in their $3^{\prime}$-untranslated regions, respectively. Expression of FoxP1 and MET was markedly reduced by ectopic miR-1 transfection. Upregulation of several miR-1 targets including FoxP1, MET, and HDAC4 in primary human HCCs and downregulation of their expression in 5-AzaC-treated HCC cells suggest their role in hepatocarcinogenesis. The inhibition of cell cycle progression and induction of apoptosis after reexpression of miR-1 are some of the mechanisms by which DNA hypomethylating agents suppress hepatocarcinoma cell growth [39]. In a human colon cancer study, miR-1 was downregulated in $84.6 \%$ of the tumors; this decrease significantly correlated with MET overexpression, particularly in metastatic tumors. Overexpression of metastasis-associated in colon cancer 1 (MACC1) and downregulation of miR-1 are associated with MET overexpression. Consistent with a suppressive role of miR-1, when ubiquitously expressed in vitro in colon cancer cells, reduced MET levels and impaired MET-induced invasive growth were seen [42].

In a separate study, miR expression in 80 colon tumors and 28 normal mucosa tissues was investigated [43]. This study identified 39 miRs demonstrating large fold change in expression levels including increased and decreased expression. miR-1 is downregulated in colon tumors as compared to the normal tissues. Based on the presence of microsatellite instability (MSI-H) and/or the absence of protein expression for human mutL homolog 1 (hMLH1) or the absence of microsatellite instability (MSS/MSI-L), the tumors were divided into two groups: defective DNA mismatch repair (dMMR) tumors (poor differentiation tumor) and proficient DNA mismatch repair (pMMR) tumors. dMMR means the presence of microsatellite instability (MSI-H) and/or the absence of protein expression for hMLH1 whereas pMMR means the absence of microsatellite instability (MSS/MSIL) and the presence of normal protein expression for hMLH1. [43]. This study demonstrated that miR-1 was further decreased in dMMR tumors relative to pMMR tumors, indicating that expression of miR-1 is associated with tumor cell differentiation. miR-1 also has a tumor suppressor function in colorectal cancer by directly downregulating the MET oncogene both at RNA and protein level, and reexpression of miR-1 leads to MET-driven reduction of cell proliferation 
and motility, identifying the miR- 1 downmodulation as one of the events that could enhance colorectal cancer progression [44]. Additionally, the reason that miR-1 is silenced in colorectal cancer is likely due to DNA hypermethylation, as miR-1 is methylated frequently in early and advanced colorectal cancer $[45,46]$. In order to identify miR signatures for gastric cancer and for predicting clinical resistance to cisplatin/fluorouracil (CF) chemotherapy, a comprehensive miR microarray analysis was performed recently by using endoscopic biopsy samples. Levels of miR-1 expression have been shown to be associated with chemosensitivity [47]. These studies have identified an oncosuppressive role of miR1 in different gastrointestinal cancers. Downregulation of miR-1 thus contributes to oncogene overexpression and to the metastatic behavior of gastrointestinal cancer cells.

4.3. miR-1 in Genitourinary Cancer. In genitourinary carcinomas, miR-1 is mainly dysregulated in prostate, bladder, and renal cancers. Prostate cancer is the most common cancer in developed countries, and it is the second leading cause of cancer deaths in men [48]. miR-1 is downregulated in prostate tumor tissue as compared to nontumor tissue by microarray analysis. Western blot analysis has confirmed that miR-1 represses its target gene exprotin 6 and protein tyrosine kinase 9 (also termed A6/twinfilin) on the protein level in two prostate cancer cell lines [49]. Little is known about the function of these two genes, but recent data suggest that both regulate cellular actin dynamic [49]. Similarly, another study demonstrated significantly lower expression of miR-1 in prostate cancer tissues [50]. Meanwhile, this study found 6 genes (TAGLN2, WDR78, C4orf34, PNP, LASS2, and STXBP4) had putative target sites for miR-1 in their $3^{\prime}$ UTR by Target Scan Program [50]. PNP (purine nucleoside phosphorylase) was highly expressed in prostate tumors as compared with nonprostate tumor tissues by RT-PCR and potentially functions as an oncogene. Overexpression of miR-1 not only inhibits prostate cancer cell proliferation, migration, wounding-healing, and invasion activity but also inhibits the expression of PNP in these cell lines [50]. Another more recent study showed miR-1 is among the most consistently downregulated miRs in primary human prostate tumors [51]. miR-1 expression is further reduced in distant metastasis and is a candidate predictor of disease recurrence. Further in vitro experiments showed miR-1 is epigenetically silenced in human prostate cancer, although the mechanisms underlying miR-1 deregulation in cancer are not well understood. Overexpression of miR-1 in these cells led to growth inhibition and downregulation of genes in pathways regulating cell cycle progression, mitosis, DNA replication/repair, and actin dynamics [51]. A gene set enrichment analysis revealed that the miR-1-mediated tumor suppressor effects are globally similar to those of histone deacetylase inhibitors. Additional data showed evidence that miR-1 alters the cellular organization of F-actin and inhibits tumor cell invasion and filopodia formation [51]. Another interesting study used an integrated functional miR-target interaction with mRNA and miR expression to infer mRNAmediated miR-miR interactions and revealed that miR-1 is a key player in regulating prostate cancer progression. miR-1 were identified as diagnostic and prognostic biomarkers in the $11 \mathrm{miRs}$ that act as tumor suppressor miRs [52]. Epithelialmesenchymal transition (EMT) is a developmental program of signaling pathways that determine commitment to epithelial and mesenchymal phenotypes. EMT processes have been implicated in benign prostatic hyperplasia and prostate cancer progression. The Slug gene has been shown to be a major regulator of mesenchymal differentiation. Slug is also a direct repressor of miR-1 transcription. Slug and miR-1 act in a self-reinforcing regulatory loop, leading to amplification of EMT. Depletion of Slug inhibited EMT during tumorigenesis, whereas ubiquitous expression of miR-1 inhibited both EMT and tumorigenesis in human and mouse model systems [53]. These extensive studies indicate that miR-1 acts as a tumor suppressor in prostate cancer by influencing multiple cancerrelated processes and by inhibiting cell proliferation and motility.

Bladder cancer is the second most common cancer of the genitourinary tract [54]. miR-1 is downregulated in bladder cancer tissues [55]. miR-1 also functions as a tumor suppressor in bladder cancer. Transfected miR-1 into bladder cancer cell lines inhibits tumor cell viability, invasion, migration activity, and proliferation [56-58]. These effects were achieved through regulating the various miR-1 targeted genes. Moreover, expression of miR-1 has been reported to promote apoptosis. Transfection of miR-1 in bladder cancer cell lines significantly increased caspase-3/7 activities. Similar results were observed with the knockdown of miR-1 targeted gene SRSF9 [58]. In another recent study by the same group, novel molecular targets regulated by miR-1 in bladder cancer were identified [59]. Genome-wide molecular target search and luciferase reporter assays showed that prothymosin- $\alpha$ (PTMA) and PNP are directly regulated by miR-1. Silencing of these two genes significantly inhibited cell proliferation and invasion and increased apoptosis in bladder cancer cells. Immunohistochemistry showed that PTMA expression levels were significantly higher in $\mathrm{BC}$ compared to normal bladder epitheliums. PTMA and PNP were identified as new target genes regulated by miR-1 in bladder cancer. These genes may function as oncogenes contributing to cell proliferation and invasion in bladder cancer [59]. PTMA is one of the miR-1 target genes involved in miR-1 inducing apoptosis. Inhibition of PTMA can accelerate apoptotic progression in cells treated with anticancer drugs [59]. Therefore targeting PTMA may have potential applications as an adjuvant in cancer chemotherapy.

4.4. miR-1 in Head and Neck Cancer. Head and neck cancer are tumors localized in oral cavity, oropharynx, hypopharynx, and larynx. In head and neck cancers, squamous cell carcinomas account for $90 \%$, collectively referred to head and neck squamous cell carcinoma (HNSCC). HNSCC has been ranked as one of the top ten cancers worldwide for the past 20 years and the survival rate has remained unchanged; half of the cases die within 5 years of diagnosis [32,60]. Researchers analyzed miR expression profiles of HNSCC and adjacent normal tissues by miR microarray, which showed six miRs (miR-21, miR-1, miR-133a, miR-205, miR-206, and let-7d) exhibiting low expression levels as compared to normal 
specimen [61]. It is hypothesized that these miRs might distinguish between different HNSCC tumor characteristics. miR-1 also inhibits head and neck cancer cell growth by targeting different miR-1 targeted genes [62-64]. For example, studies have investigated the functional significance of miR-1 in HNSCC cells and identified miR-1-regulated novel cancer pathways. Gain-of-function studies using miR1 revealed significant decreases in HNSCC cell proliferation, invasion, and migration. In addition, the promotion of cell apoptosis and cell cycle arrest was demonstrated following miR-1 transfection of cancer cells. A search for the targets of miR-1 revealed that transgelin 2 (TAGLN2) was directly regulated by miR-1. Silencing of TAGLN2 significantly inhibited cell proliferation and invasion in HNSCC cells [65]. Downregulation of miR-1 and upregulation of TAGLN2 were confirmed in HNSCC clinical specimens [65]. These data indicate that miR-1 is a tumor suppressive miR in HNSCC, and TAGLN2 may have an oncogenic function regulated by miR-1. This identification of novel miR-1-regulated cancer pathways could provide new insights into potential molecular mechanisms of HNSCC carcinogenesis. Another study found miR-1 expression is significantly downregulated in thyroid carcinomas as compared to normal thyroid tissue, suggesting miR-1 may also play a role in thyroid carcinogenesis [66].

4.5. miR-1 in Sarcoma. Sarcoma is a malignant tumor which forms in the connective or supportive tissues of the body, including bone, cartilage, fat, muscle, or blood vessels. Most miR-1 and sarcoma studies were on rhabdomyosarcoma (RMS). RMS is the most common soft tissue sarcoma in the pediatric malignancies and is classified into embryonal, alveolar, and pleomorphic RMS based on histological features [67]. Studies have found that many miRs are dysregulated in RMS [68]. Of those miRs, miR-1, miRNA-206, miRNA$133 \mathrm{a}$, and miRNA-133b are the members of the musclespecific miRs and often show decreased expression in RMS. Downregulation of miR-1 in RMS has been confirmed by northern blot analysis. Overexpression of miR-1 may inhibit rhabdomyosarcoma cell migration and proliferation through apoptosis and arrest cell cycle in vitro and restrain tumor growth in vivo [69]. More recent studies have shown that transfection of miR-1 in rhabdomyosarcoma cells suppressed c-Met expression, leading to inhibited cell proliferation and tumor growth [70, 71]. Elevated levels of PAX3 and cell proliferation genes are characteristic features of RMS [72]. Studies have found downregulation of miR-1 stabilizes the expression of PAX3 and CCND2 in both embryonal (ERMS) and alveolar (ARMS) RMS types. Transfection of miR-1 in ERMS cell line showed significant downregulation of PAX3 protein expression [69]. miR-1 is a potential regulator of PAX3 expression by binding to its $3^{\prime} U T R$. PAX3 plays a critical role in myogenesis, and increased expression of PAX3 is implicated in the pathogenesis of RMS. Specifically, in ARMS, fusion transcript PAX3-FOXO1 produces a protein product, within which the structural integrity of both PAX3 DNA-binding regions, the paired box and homeodomain, is retained. However, the $3^{\prime}$ UTR region of PAX3 is lost during the formation of this functional fusion transcript [72]. In this context, the loss of $3^{\prime}$ UTR region of PAX3 due to formation of fusion transcript may allow the fusion transcript PAX3FOXO1 to escape miR-1-mediated regulation. The author proposed that loss of $3^{\prime}$ UTR of PAX3 and/or the downregulation of miR-1 are oncogenic events in rhabdomyosarcomagenesis. miR-1 can also regulate the expression of CCND2, a cell cycle gene [72]. Elevated CCND2 levels are observed in various cancers and are implicated in cell proliferation. miR1 also regulates CCND2 transcript and protein levels. miR expression in chordoma-derived cell lines and chordoma tissue has been reported recently by using $\mathrm{miR}$ microarray technology [14]. Chordoma is an unusual rare tumor of bone in which the traditional treatment of surgical resection and radiation is often difficult, and there are no effective systemic therapies available [14]. Human chordoma tissues and cell lines can be distinguished from normal muscle tissue by comparing miR expression profiles. Expression of miR1 was markedly decreased in both chordoma tissues and cell lines. When chordoma cell lines were transfected with miR-1, downregulation of known miR-1 targets was observed. These targets included Met and HDAC4 two genes that were observed to be overexpressed in chordoma. These results demonstrate that miR-1 may have a functional effect on chordoma tumor pathogenesis $[14,73]$. miR-1 has also been found to be downregulated in osteosarcoma cell lines [74].

\section{Therapeutic Potential of miR-1 Modulation}

The rationale for exploring the therapeutic potential of miR-1 is based on the observation that a single miR-1 can regulate multiple oncogenes and oncogenic pathways that are commonly deregulated in different cancers (Figure 3). Several experimental approaches can identify actual miR-1 target genes in tumor cells. By using bioinformatic prediction programs, qRT-PCR, western blotting, and reporter assays, recent investigations have identified several oncogene and oncogenic pathway targets of miR-1 in different human cancers (Table 2). These targets potentially contribute to specific functional readouts of miR-1 as described above. For example, enforced expression of miR-1 in lung, colon, RMS, and chordoma cells dramatically suppressed Met expression and inhibited tumor cell growth $[42,44,69]$. Similar results were found in other types of cancer [14, 38].

miR-1 is consistently dysregulated across many cancers. The dysregulated miR-1 is not limited to a particular tumor type and, in some cases, the aberrantly expressed miRs correlate with clinical status such as the tumor stage and patient survival. Additionally, recent studies have observed a functional contribution of miR-1 to cellular transformation, tumorigenesis, apoptosis, and drug sensitivity. miR-1 provide critical functions downstream of classic oncogenic signaling pathways such as those controlled by Met, HDAC4, PIM-1, Wnt, Cyclin D, FOXP1, Slug, and TAGLN2. Finally, functional studies have directly documented the potent antitumorigenic activity of miR-1 both in vitro and in vivo. These exciting findings not only improve our understanding of the molecular mechanisms of human cancer but also provide a new class of potential molecular targets. As aberrantly expressed miR-1 plays key roles in the development of human cancer, 

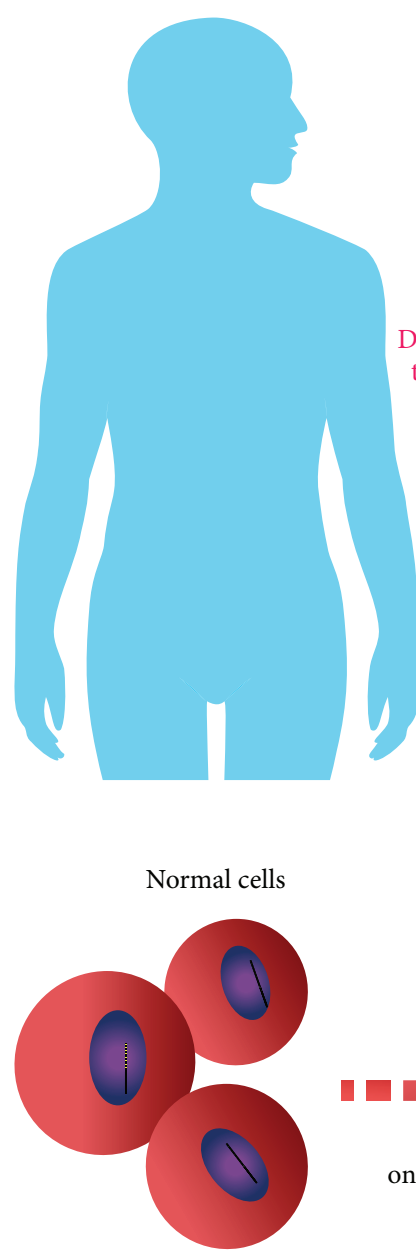

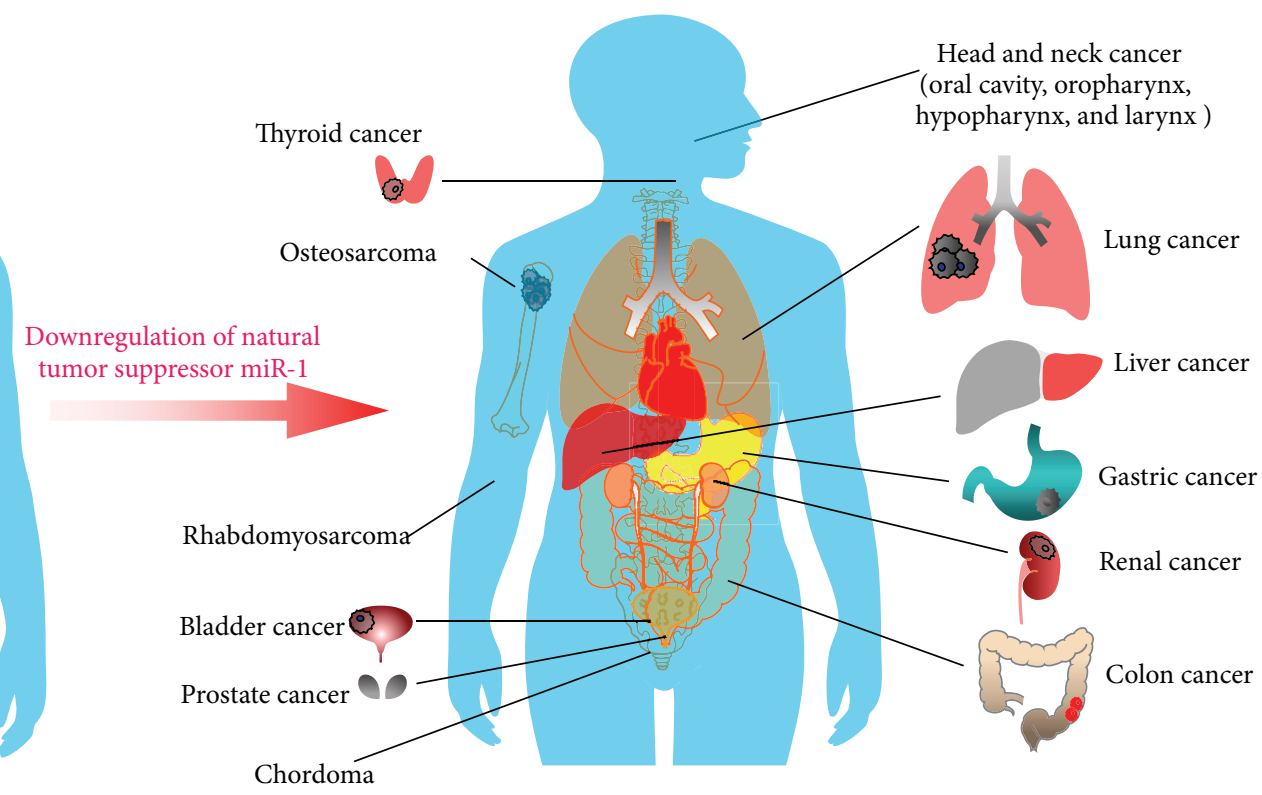

(a)

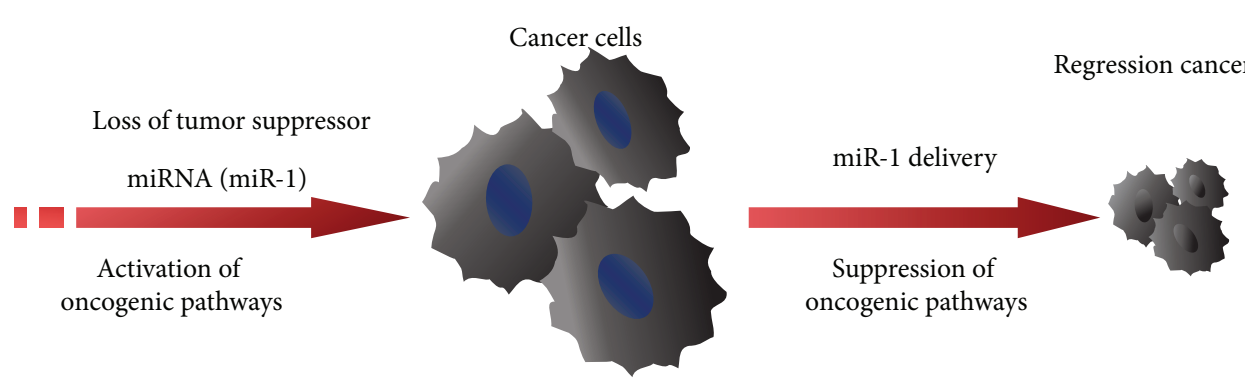

(b)

FIGURE 3: Aberrant expression of miR-1 in human cancers and its therapeutic potentials. (a) Association of decreased expression of miR-1 in different human cancers. (b) Loss of a tumor suppressor miR-1 leads to activation of oncogenic pathways and tumorigenesis. Delivery of miR-1 into the cytoplasm of tumor cells targeting oncogenes and subsequently suppressing tumor growth.

TABLE 2: Oncogenes and oncogenic pathway targets of miR-1 in cancers.

\begin{tabular}{|c|c|c|c|c|}
\hline Gene name & Genbank accession number & Chromosome location & Functions & $\begin{array}{c}\text { Reference } \\
\text { number }\end{array}$ \\
\hline Met & NM_000245.2 & $7 \mathrm{q} 31$ & Proto-oncogenic receptor tyrosine kinase & {$[42,44,68]$} \\
\hline HDAC4 & NM_006037.3 & $2 \mathrm{q} 37.3$ & Histone deacetylase activity; represses transcription & {$[14,31,39]$} \\
\hline Pim-1 & NM_002648.3 & $6 \mathrm{p} 21.2$ & Proto-oncogene & {$[33]$} \\
\hline FOXP1 & NM_001244810.1 & 3 p14.1 & Regulate gene transcription; tumor suppressor & {$[33,39]$} \\
\hline TAGLN2 & NM_003564.1 & $1 \mathrm{q} 21-\mathrm{q} 25$ & Earliest marker of differentiated smooth muscle & {$[50,56,64]$} \\
\hline PNP & NM_000270.3 & $14 q 13.1$ & Purine metabolism & {$[50,58]$} \\
\hline PTMA & NM_002823.4 & $2 \mathrm{q} 37.1$ & Enhance cell-mediated immunity & [58] \\
\hline CXCR4 & NM_001008540.1 & $2 \mathrm{q} 21$ & Chemokine receptor & {$[65]$} \\
\hline CCND2 & NM_001759.3 & $12 \mathrm{p} 13$ & Regulator of cyclin-dependent kinase & {$[65,71]$} \\
\hline SRSF9 & NM_003769.2 & $12 \mathrm{q} 24.31$ & & {$[57]$} \\
\hline FN1 & NM_212482.1 & $2 \mathrm{q} 34$ & Involved in cell adhesion, growth, and migration & [61] \\
\hline ETS1 & NM_001143820.1 & $11 \mathrm{q} 23.3$ & Proto-oncogene & {$[40]$} \\
\hline Endothelin 1 & NM_001955.4 & $6 \mathrm{p} 24.1$ & Involved in vascular disorders & {$[41]$} \\
\hline Slug & NM_003068.4 & $8 q 11$ & Transcriptional repressor and has antiapoptotic activity & {$[38]$} \\
\hline CXCL12 & NM_199168.3 & 10q11.1 & Chemotactic for lymphocytes & [65] \\
\hline
\end{tabular}


correcting miR-1 dysregulation and deficiencies by restoring miR-1 function will provide a significant advance in cancer therapy.

Downmodulation of miR-1 has been identified as one of the events that enhance colorectal cancer progression [44]. miR-1 has tumor suppressor functions in colorectal cancer by directly downregulating MET oncogene both at RNA and protein level. Restoration of miR-1 expression leads to METdriven reduction of cell proliferation and motility [44]. miR1 has also been shown to act upstream from $\beta$-catenin of the canonical Wnt pathway [75]. The canonical Wnt pathway includes a pivotal cytoplasmic complex composed of APC, GSK $3 \beta$, and Axin. $\beta$-Catenin may be phosphorylated by this complex and then degraded after ubiquitination. Activation of canonical Wnt signaling may cause accumulation of $\beta$ beta-catenin in the cytoplasm and then translocate to the nucleus [76]. Aberrant regulation of the Wnt signalling pathway has emerged as a prevalent theme in cancer biology, indicating that activation of this pathway may play an important role in tumor development. As $\mathrm{Wnt} / \beta$-catenin signaling is tightly regulated at multiple cellular levels, this pathway offers many targeting nodal points for cancer drug development. miR-1 inhibits cell proliferation and viability during selection of human colon cancer cell lines that exhibit dysregulated Wnt signaling. By transducing miR-1 expressing lentiviruses into primary mammary organoids derived from muscle from which these tumors arise, reexpression of miR1 rescued the myogenic differentiation program and blocked the tumorigenic phenotype [71]. These data support the notion that miR-1 holds substantial clinical potential as differentiation therapy for RMS and perhaps other solid tumors. miR-1 reexpression therapy constitutes a novel approach to inhibit oncogenes and arrest tumor development [77]. In lung cancer, reexpression of miR-1 induced apoptosis in cancer cells in response to the potent anticancer drug doxorubicin [75]. Enhanced activation of caspases 3 and 7, cleavage of their substrate PARP-1, and depletion of antiapoptotic Mcl1 contributed to the sensitivity of miR-1-expressing cells to doxorubicin. Conductin-lacZ mice significantly reduced the expression of the Wnt-sensitive $\beta$-gal reporter [75]. These findings suggest the potential use of Wnt-modulating miR1 as diagnostic and therapeutic tools in Wnt-dependent cancers, such as colorectal cancer. More recently, Slug has been identified as a miR-1 target in lung cancer A549 cells by TargetScan and picTar and a luciferase reporter assay with plasmids containing luciferase-Slug $3^{\prime}$-UTR [37]. These results suggest that reexpression of miR-1 may be an effective therapy that prevents cancer malignancy by converting cells from a mesenchymal phenotype to an epithelial phenotype via the downregulation of Slug. Moreover, induction of artificial transcription factor (ATF) expression in breast cancer in vivo by doxycycline resulted in 50\% reduction in tumor growth and completely abolished tumor cell colonization [78]. Interestingly, ATF CDNA induction led to the reactivation of tumor suppressive miRs such as miR-1 [78].

In order for miR-1 to be effective as a cancer target, the therapeutic agents must be administered systemically, allow for specific and efficient delivery to the tumor tissue, and be taken up by tumor cells into the cytoplasm, where they can be available in intact form. While use of miR-1 has been effective for short-term gene inhibition in mammalian cell lines, its use for stable long-term transcriptional knockdown of target genes has been shown to be problematic $[79,80]$. Similar to other nucleic acid constructs, miR-1 has stability and delivery problems for clinical applications. Like siRNAs, miRs have poor cellular membrane permeability and limited stability in vivo and intracellular delivery in tumor cells upon systemic administration $[21,22]$. In order to translate miR-1 from an experimental approach to a clinical-viable therapeutic strategy that can benefit cancer patients, a specific and efficient delivery system is needed. Currently, plasmid and viral-based vectors are being used for miR delivery $[21,22]$. Despite their high transduction efficiency, viral delivery approaches face serious challenges. Several gene therapy trials based on viral delivery systems have produced adverse effects questioning their safety $[81,82]$. In addition, high costs for producing large amounts of viral stocks for clinical use and limited quantities of nucleic acids that can be packaged for therapy also limit the applications of viral delivery systems. Therefore, developing safe and effective nonviral miR-1 delivery systems is very important. Recently, a robust method for delivering unmodified miRs into cells has been developed by using cysteamine-functionalized gold nanoparticles (AuNPs) [83]. The efficiency of this method has been validated in two different tumor models and it showed that the best formulation of $\operatorname{miR}(1)-A u N P(10)-S$ PEG(0.5) had the highest payload (10-20-fold higher than lipofectamine, a toxic transfection reagent for miRs in vitro), lowest toxicity (98\% of cell viability following treatment), efficient uptake (96\% uptake rate), fastest endosomal escape, and increased half-lives (at least 5 days) impacting cell proliferation and patterns of target gene expression [83]. These studies represent an essential step toward the advancement of nanotechnology-based miR delivery systems and evaluation of their therapeutic potentials in preclinical models.

\section{Conclusion}

There are now numerous examples linking dysregulated expression of miRs to cancer and its important role in human cancer. As reviewed above, miR-1 contributes to several biological processes of the tumor cell, including differentiation, proliferation, and apoptosis. Recently, studies from our group and others have shown that downregulation of miR-1 is one the most frequent events in some cancers. Herein, we have reviewed the expression of miR-1 and miR-1 regulated molecular targets in various types of cancer, and it is anticipated that further research will provide more convincing support for further miR-1 based therapy strategies.

\section{Abbreviations}

miR: MicroRNA

mRNA: Messenger RNA

miR-1: miRNA-1

UTR: Untranslated region. 


\section{Conflict of Interests}

The authors declare that there is no conflict of interests regarding the publication of this paper.

\section{References}

[1] D. P. Bartel, "MicroRNAs: genomics, biogenesis, mechanism, and function," Cell, vol. 116, no. 2, pp. 281-297, 2004.

[2] H.-W. Hwang and J. T. Mendell, "MicroRNAs in cell proliferation, cell death, and tumorigenesis," British Journal of Cancer, vol. 94, no. 6, pp. 776-780, 2006.

[3] C. M. Croce, "Causes and consequences of microRNA dysregulation in cancer," Nature Reviews Genetics, vol. 10, no. 10, pp. 704-714, 2009.

[4] M. M. Alam and L. A. O’Neill, "MicroRNAs and the resolution phase of inflammation in macrophages," European Journal of Immunology, vol. 41, no. 9, pp. 2482-2485, 2011.

[5] R. C. Lee, R. L. Feinbaum, and V. Ambros, "The C. elegans heterochronic gene lin-4 encodes small RNAs with antisense complementarity to lin-14," Cell, vol. 75, no. 5, pp. 843-854, 1993.

[6] V. N. Kim, "MicroRNA biogenesis: coordinated cropping and dicing," Nature Reviews Molecular Cell Biology, vol. 6, no. 5, pp. 376-385, 2005.

[7] T.-C. Chang and J. T. Mendell, "MicroRNAs in vertebrate physiology and human disease," Annual Review of Genomics and Human Genetics, vol. 8, pp. 215-239, 2007.

[8] B. Zhang, Q. Wang, and X. Pan, "MicroRNAs and their regulatory roles in animals and plants," Journal of Cellular Physiology, vol. 210, no. 2, pp. 279-289, 2007.

[9] B. M. Ryan, A. I. Robles, and C. C. Harris, "Genetic variation in microRNA networks: the implications for cancer research," Nature Reviews Cancer, vol. 10, no. 6, pp. 389-402, 2010.

[10] W. Filipowicz, S. N. Bhattacharyya, and N. Sonenberg, "Mechanisms of post-transcriptional regulation by microRNAs: are the answers in sight?" Nature Reviews Genetics, vol. 9, no. 2, pp. 102$114,2008$.

[11] L. He and G. J. Hannon, "MicroRNAs: small RNAs with a big role in gene regulation," Nature Reviews Genetics, vol. 5, no. 7, pp. 522-531, 2004.

[12] C. Liu, K. Kelnar, A. V. Vlassov, D. Brown, J. Wang, and D. G. Tang, "Distinct microRNA expression profiles in prostate cancer stem/progenitor cells and tumor-suppressive functions of let-7," Cancer Research, vol. 72, no. 13, pp. 3393-3404, 2012.

[13] Z. Duan, E. Choy, D. Harmon et al., "MicroRNA-199a-3p is downregulated in human osteosarcoma and regulates cell proliferation and migration," Molecular Cancer Therapeutics, vol. 10, no. 8, pp. 1337-1345, 2011.

[14] Z. Duan, E. Choy, G. Petur Nielsen et al., "Differential expression of microRNA (miRNA) in chordoma reveals a role for miRNA-1 in met expression," Journal of Orthopaedic Research, vol. 28, no. 6, pp. 746-752, 2010.

[15] N. Ratert, H. A. Meyer, M. Jung et al., "Reference miRNAs for miRNAome analysis of urothelial carcinomas," PLOS ONE, vol. 7, no. 6, Article ID e39309, 2012.

[16] M.-F. Lang, S. Yang, C. Zhao et al., "Genome-wide profiling identified a set of miRNAs that are differentially expressed in glioblastoma stem cells and normal neural stem cells," PLoS ONE, vol. 7, no. 4, Article ID e36248, 2012.

[17] Y. Akao, Y. Nakagawa, I. Hirata et al., "Role of anti-oncomirs miR-143 and-145 in human colorectal tumors," Cancer Gene Therapy, vol. 17, no. 6, pp. 398-408, 2010.
[18] S. M. Johnson, H. Grosshans, J. Shingara et al., "RAS is regulated by the let-7 microRNA family," Cell, vol. 120, no. 5, pp. 635-647, 2005.

[19] M. T. N. Le, C. Teh., N. Shyh-Chang et al., "MicroRNA-125b is a novel negative regulator of p53," Genes \& Development, vol. 23, no. 7, pp. 862-876, 2009.

[20] Y. Zhang, J.-S. Gao, X. Tang et al., "MicroRNA 125a and its regulation of the p53 tumor suppressor gene," FEBS Letters, vol. 583, no. 22, pp. 3725-3730, 2009.

[21] R. Garzon, G. Marcucci, and C. M. Croce, "Targeting microRNAs in cancer: rationale, strategies and challenges," Nature Reviews Drug Discovery, vol. 9, no. 10, pp. 775-789, 2010.

[22] A. G. Bader, D. Brown, and M. Winkler, "The promise of microRNA replacement therapy," Cancer Research, vol. 70, no. 18, pp. 7027-7030, 2010.

[23] N. Nakajima, T. Takahashi, R. Kitamura et al., "MicroRNA1 facilitates skeletal myogenic differentiation without affecting osteoblastic and adipogenic differentiation," Biochemical and Biophysical Research Communications, vol. 350, no. 4, pp. 10061012, 2006.

[24] J. Gagan, B. K. Dey, R. Layer, Z. Yan, and A. Dutta, "Notch3 and Mef2c are mutually antagonistic via Mkp1 and miR-1/206 in differentiating myoblasts," The Journal of Biological Chemistry, 2012.

[25] Y. Mishima, C. Stahlhut, and A. J. Giraldez, "miR-1-2 Gets to the heart of the matter," Cell, vol. 129, no. 2, pp. 247-249, 2007.

[26] Y. Zhao, J. F. Ransom, A. Li et al., "Dysregulation of cardiogenesis, cardiac conduction, and cell cycle in mice lacking miRNA1-2," Cell, vol. 129, no. 2, pp. 303-317, 2007.

[27] G. Long, F. Wang, Q. Duan et al., "Human circulating microRNA-1 and microRNA-126 as potential novel indicators for acute myocardial infarction," International Journal of Biological Sciences, vol. 8, no. 6, pp. 811-818, 2012.

[28] A. E. Belevych, S. E. Sansom, R. Terentyeva et al., "MicroRNA-1 and -133 increase arrhythmogenesis in heart failure by dissociating phosphatase activity from RyR2 complex," PLoS ONE, vol. 6, no. 12, Article ID e28324, 2011.

[29] R. Kumarswamy, A. R. Lyon, I. Volkmann et al., "SERCA2a gene therapy restores microRNA-1 expression in heart failure via an Akt/FoxO3A-dependent pathway," European Heart Journal, vol. 33, no. 9, pp. 1067-1075, 2012.

[30] E. Boštjančič, N. Zidar, D. Štajer, and D. Glavač, "MicroRNAs miR-1, miR-133a, miR-133b and miR-208 are dysregulated in human myocardial infarction," Cardiology, vol. 115, no. 3, pp. 163-169, 2010.

[31] A. Lewis, J. Riddoch-Contreras, S. A. Natanek et al., "Downregulation of the serum response factor/miR-1 axis in the quadriceps of patients with COPD," Thorax, vol. 67, no. 1, pp. 26-34, 2012.

[32] R. Siegel, D. Naishadham, and A. Jemal, “Cancer statistics, 2012," CA Cancer Journal for Clinicians, vol. 62, no. 1, pp. 10-29, 2012.

[33] T. Melkamu, X. Zhang, J. Tan, Y. Zeng, and F. Kassie, "Alteration of microRNA expression in vinyl carbamate-induced mouse lung tumors and modulation by the chemopreventive agent indole-3-carbinol," Carcinogenesis, vol. 31, no. 2, pp. 252-258, 2010.

[34] M. W. Nasser, J. Datta, G. Nuovo et al., "Down-regulation of micro-RNA-1 (miR-1) in lung cancer: suppression of tumorigenic property of lung cancer cells and their sensitization to doxorubicin-induced apoptosis by miR-1," The Journal of Biological Chemistry, vol. 283, no. 48, pp. 33394-33405, 2008. 
[35] Q. Zhao, B. Zhang, Y. Shao et al., "Correlation between the expression levels of miR-1 and PIK3CA in non-small-cell lung cancer and their relationship with clinical characteristics and prognosis," Future Oncology, vol. 10, no. 1, pp. 49-57, 2014.

[36] Q. Q. Yu, H. Wu, X. Huang et al., "miR-1 targets PIK3CA and inhibits tumorigenic properties of A549 cells," Biomedicine \& Pharmacotherapy, vol. 68, no. 2, pp. 155-161, 2014.

[37] E. Tominaga, K. Yuasa, S. Shimazaki, and T. Hijikata, "MicroRNA-1 targets Slug and endows lung cancer A549 cells with epithelial and anti-tumorigenic properties," Experimental Cell Research, vol. 319, no. 3, pp. 77-88, 2013.

[38] Z. Hu, X. Chen, Y. Zhao et al., "Serum microRNA signatures identified in a genome-wide serum microRNA expression profiling predict survival of non-small-cell lung cancer," Journal of Clinical Oncology, vol. 28, no. 10, pp. 1721-1726, 2010.

[39] J. Datta, H. Kutay, M. W. Nasser et al., "Methylation mediated silencing of microRNA-1 gene and its role in hepatocellular carcinogenesis," Cancer Research, vol. 68, no. 13, pp. 5049-5058, 2008.

[40] W. Wei, Z. Hu, H. Fu et al., "MicroRNA-1 and microRNA499 downregulate the expression of the etsl proto-oncogene in HepG2 cells," Oncology Reports, vol. 28, no. 2, pp. 701-706, 2012.

[41] D. Li, P. Yang, H. Li et al., "MicroRNA-1 inhibits proliferation of hepatocarcinoma cells by targeting endothelin-1," Life Sciences, vol. 91, no. 11-12, pp. 440-447, 2012.

[42] C. Migliore, V. Martin, V. P. Leoni et al., "miR-1 downregulation cooperates with MACC1 in promoting MET overexpression in human colon cancer," Clinical Cancer Research, vol. 18, no. 3, pp. 737-747, 2012.

[43] A. L. Sarver, A. J. French, P. M. Borralho et al., "Human colon cancer profiles show differential microRNA expression depending on mismatch repair status and are characteristic of undifferentiated proliferative states," BMC Cancer, vol. 9, article 401, 2009.

[44] J. F. Reid, V. Sokolova, E. Zoni et al., "miRNA profiling in colorectal cancer highlights miR-1 involvement in METdependent proliferation," Molecular Cancer Research, vol. 10, no. 4, pp. 504-515, 2012.

[45] W. S. Chen, C. M. Leung, H. W. Pan et al., "Silencing of miR-11 and miR-133a-2 cluster expression by DNA hypermethylation in colorectal cancer," Oncology Reports, vol. 28, no. 3, pp. 10691076, 2012.

[46] H. Suzuki, S. Takatsuka, H. Akashi et al., "Genome-wide profiling of chromatin signatures reveals epigenetic regulation of microRNA genes in colorectal cancer," Cancer Research, vol. 71, no. 17, pp. 5646-5658, 2011.

[47] C. Kim, H. K. Kim, R. L. Rettig et al., "miRNA signature associated with outcome of gastric cancer patients following chemotherapy," BMC Medical Genomics, vol. 4, article 79, 2011.

[48] M. R. Cooperberg, J. M. Broering, and P. R. Carroll, "Risk assessment for prostate cancer metastasis and mortality at the time of diagnosis," Journal of the National Cancer Institute, vol. 101, no. 12, pp. 878-887, 2009.

[49] S. Ambs, R. L. Prueitt, M. Yi et al., "Genomic profiling of microRNA and messenger RNA reveals deregulated microRNA expression in prostate cancer," Cancer Research, vol. 68, no. 15, pp. 6162-6170, 2008.

[50] S. Kojima, T. Chiyomaru, K. Kawakami et al., "Tumour suppressors miR-1 and miR-133a target the oncogenic function of purine nucleoside phosphorylase (PNP) in prostate cancer," British Journal of Cancer, vol. 106, no. 2, pp. 405-413, 2012.
[51] R. S. Hudson, M. Yi, D. Esposito et al., "MicroRNA-1 is a candidate tumor suppressor and prognostic marker in human prostate cancer," Nucleic Acids Research, vol. 40, no. 8, pp. 36893703, 2012.

[52] M. Alshalalfa, "MicroRNA response elements-mediated miRNA-miRNA interactions in prostate cancer," Advances in Bioinformatics, vol. 2012, Article ID 839837, 10 pages, 2012.

[53] Y. N. Liu, J. J. Yin, W. Abou-Kheir et al., "miR-1 and miR-200 inhibit EMT via Slug-dependent and tumorigenesis via Slugindependent mechanisms," Oncogene, vol. 32, no. 3, pp. 296306, 2013.

[54] S. Al-Sukhun and M. Hussain, "Current understanding of the Biology of advanced bladder cancer," Cancer, vol. 97, no. 8, supplement, pp. 2064-2075, 2003.

[55] G. Pignot, G. Cizeron-Clairac, S. Vacher et al., "Microrna expression profile in a large series of bladder tumors: identification of a 3-mirna signature associated with aggressiveness of muscle-invasive bladder cancer," International Journal of Cancer, vol. 132, no. 11, pp. 2479-2491, 2013.

[56] T. Chiyomaru, H. Enokida, K. Kawakami et al., "Functional role of LASP1 in cell viability and its regulation by microRNAs in bladder cancer," Urologic Oncology, vol. 30, no. 4, pp. 434-443, 2012.

[57] H. Yoshino, T. Chiyomaru, H. Enokida et al., "The tumoursuppressive function of miR-1 and miR-133a targeting TAGLN2 in bladder cancer," British Journal of Cancer, vol. 104, no. 5, pp. 808-818, 2011.

[58] H. Yoshino, H. Enokida, T. Chiyomaru et al., "Tumor suppressive microRNA-1 mediated novel apoptosis pathways through direct inhibition of splicing factor serine/arginine-rich 9 (SRSF9/SRp30c) in bladder cancer," Biochemical and Biophysical Research Communications, vol. 417, no. 1, pp. 588-593, 2012.

[59] T. Yamasaki, H. Yoshino, H. Enokida et al., "Novel molecular targets regulated by tumor suppressors microRNA-1 and microRNA-133a in bladder cancer," International Journal of Oncology, vol. 40, no. 6, pp. 1821-1830, 2012.

[60] C. C. Boring, T. S. Squires, and T. Tong, "Cancer statistics, 1991," Boletin de la Asociacion Medica de Puerto Rico, vol. 83, no. 6, pp. 225-242, 1991.

[61] G. Childs, M. Fazzari, G. Kung et al., "Low-level expression of microRNAs let-7d and miR-205 are prognostic markers of head and neck squamous cell carcinoma," The American Journal of Pathology, vol. 174, no. 3, pp. 736-745, 2009.

[62] F. Wang, G. Song, M. Liu, X. Li, and H. Tang, "miRNA-1 targets fibronectinl and suppresses the migration and invasion of the HEp2 laryngeal squamous carcinoma cell line," FEBS Letters, vol. 585, no. 20, pp. 3263-3269, 2011.

[63] N. Nohata, T. Hanazawa, N. Kikkawa et al., "Identification of novel molecular targets regulated by tumor suppressive miR-1/miR-133a in maxillary sinus squamous cell carcinoma," International Journal of Oncology, vol. 39, no. 5, pp. 1099-1107, 2011.

[64] C.-D. Wu, Y.-S. Kuo, H.-C. Wu, and C.-T. Lin, "MicroRNA-1 induces apoptosis by targeting prothymosin alpha in nasopharyngeal carcinoma cells," Journal of Biomedical Science, vol. 18, no. 1 , article 80, 2011.

[65] N. Nohata, Y. Sone, T. Hanazawa et al., "miR-1 as a tumor suppressive microRNA targeting TAGLN2 in head and neck squamous cell carcinoma," Oncotarget, vol. 2, no. 1-2, pp. 29-42, 2011.

[66] V. Leone, D. D’Angelo, I. Rubio et al., "miR-1 is a tumor suppressor in thyroid carcinogenesis targeting CCND2, CXCR4, and 
SDF-1 $\alpha$," Journal of Clinical Endocrinology and Metabolism, vol. 96, no. 9, pp. E1388-E1398, 2011.

[67] A. Ferrari, P. Dileo, M. Casanova et al., "Rhabdomyosarcoma in adults: a retrospective analysis of 171 patients treated at a single institution," Cancer, vol. 98, no. 3, pp. 571-580, 2003.

[68] M. Miyachi, K. Tsuchiya, H. Yoshida et al., "Circulating musclespecific microRNA, miR-206, as a potential diagnostic marker for rhabdomyosarcoma," Biochemical and Biophysical Research Communications, vol. 400, no. 1, pp. 89-93, 2010.

[69] D. Yan, X. D. Dong, X. Chen et al., "MicroRNA-1/206 targets cmet and inhibits rhabdomyosarcoma development," The Journal of Biological Chemistry, vol. 284, no. 43, pp. 29596-29604, 2009.

[70] P. K. Rao, E. Missiaglia, L. Shields et al., "Distinct roles for miR-1 and miR-133a in the proliferation and differentiation of rhabdomyosarcoma cells," FASEB Journal, vol. 24, no. 9, pp. 3427-3437, 2010.

[71] R. Taulli, F. Bersani, V. Foglizzo et al., "The muscle-specific microRNA miR-206 blocks human rhabdomyosarcoma growth in xenotransplanted mice by promoting myogenic differentiation," Journal of Clinical Investigation, vol. 119, no. 8, pp. 23662378, 2009.

[72] L. Li, A. L. Sarver, S. Alamgir, and S. Subramanian, "Downregulation of microRNAs miR-1, -206 and -29 stabilizes PAX3 and CCND2 expression in rhabdomyosarcoma," Laboratory Investigation, vol. 92, no. 4, pp. 571-583, 2012.

[73] Z. Duan, J. Shen, X. Yang et al., "Prognostic significance of miRNA-1 (miR-1) expression in patients with chordoma," Journal of Orthopaedic Research, vol. 32, no. 5, pp. 695-701, 2014.

[74] H. M. Namlos, L. A. Meza-Zepeda, T. Baroy et al., "Modulation of the osteosarcoma expression phenotype by MicroRNAs," PLoS ONE, vol. 7, no. 10, Article ID e48086, 2012.

[75] R. Anton, S. S. Chatterjee, J. Simundza, P. Cowin, and R. DasGupta, "A systematic screen for micro-RNAs regulating the canonical Wnt pathway," PLoS ONE, vol. 6, no. 10, Article ID e26257, 2011.

[76] R. Z. Karim, G. M. K. Tse, T. C. Putti, R. A. Scolyer, and C. S. Lee, "The significance of the Wnt pathway in the pathology of human cancers," Pathology, vol. 36, no. 2, pp. 120-128, 2004.

[77] P. J. Mishra and G. Merlino, "MicroRNA reexpression as differentiation therapy in cancer," Journal of Clinical Investigation, vol. 119, no. 8, pp. 2119-2123, 2009.

[78] A. S. Beltran, A. Russo, H. Lara, C. Fan, P. M. Lizardi, and P. Blancafort, "Suppression of breast tumor growth and metastasis by an engineered transcription factor," PLoS ONE, vol. 6, no. 9, Article ID e24595, 2011.

[79] K. Tiemann and J. J. Rossi, "RNAi-based therapeutics-current status, challenges and prospects," EMBO Molecular Medicine, vol. 1, no. 3, pp. 142-151, 2009.

[80] K. A. Whitehead, R. Langer, and D. G. Anderson, "Knocking down barriers: advances in siRNA delivery," Nature Reviews Drug Discovery, vol. 8, no. 2, pp. 129-138, 2009.

[81] D. Ferber, "Gene therapy: safer and virus-free?" Science, vol. 294, no. 5547, pp. 1638-1642, 2001.

[82] R. Waehler, S. J. Russell, and D. T. Curiel, "Engineering targeted viral vectors for gene therapy," Nature Reviews Genetics, vol. 8, no. 8, pp. 573-587, 2007.

[83] R. Ghosh, L. C. Singh, J. M. Shohet, and P. H. Gunaratne, "A gold nanoparticle platform for the delivery of functional microRNAs into cancer cells," Biomaterials, vol. 34, no. 3, pp. 807-816, 2013. 


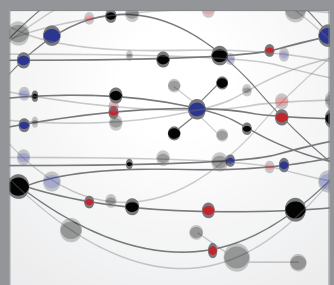

The Scientific World Journal
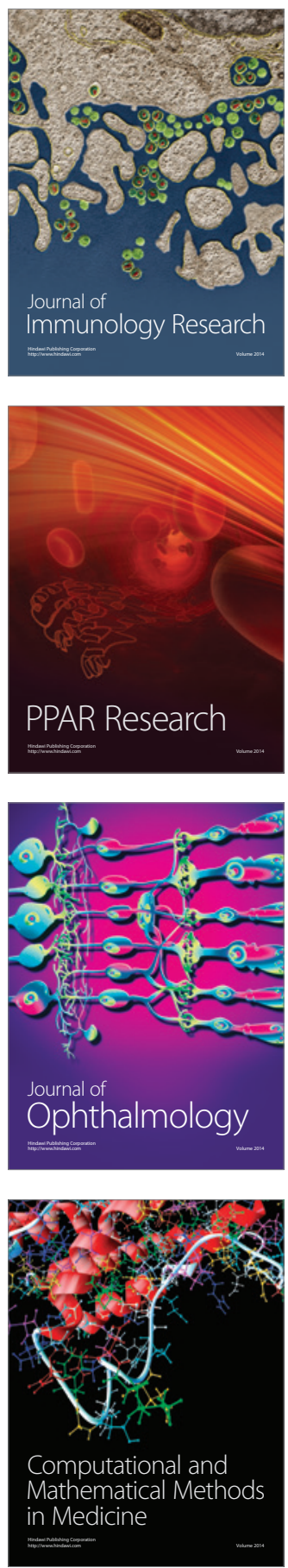

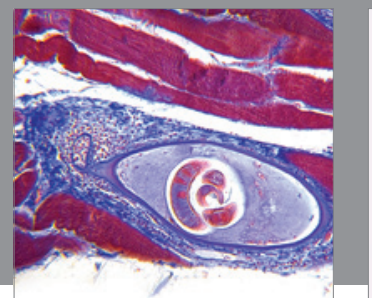

Gastroenterology

Research and Practice
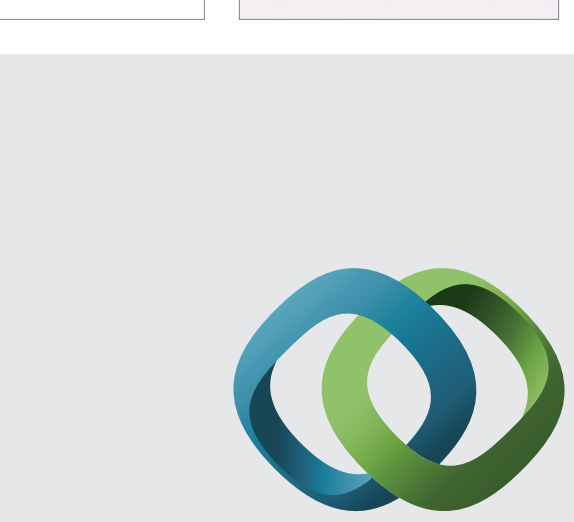

\section{Hindawi}

Submit your manuscripts at

http://www.hindawi.com
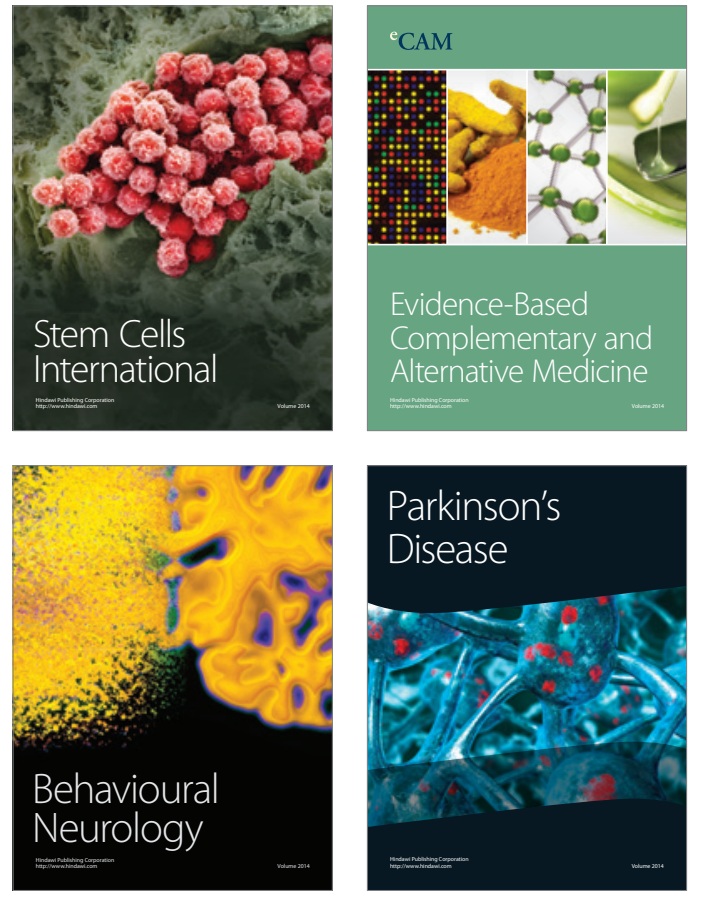
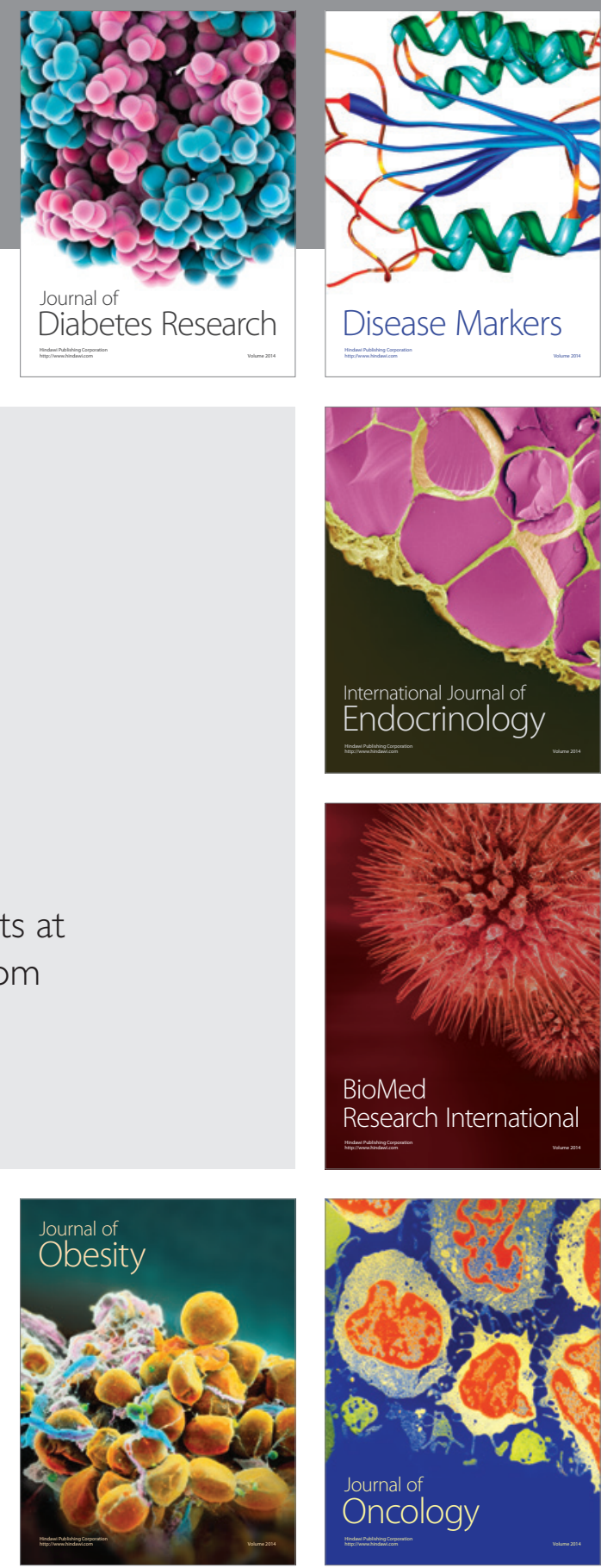

Disease Markers
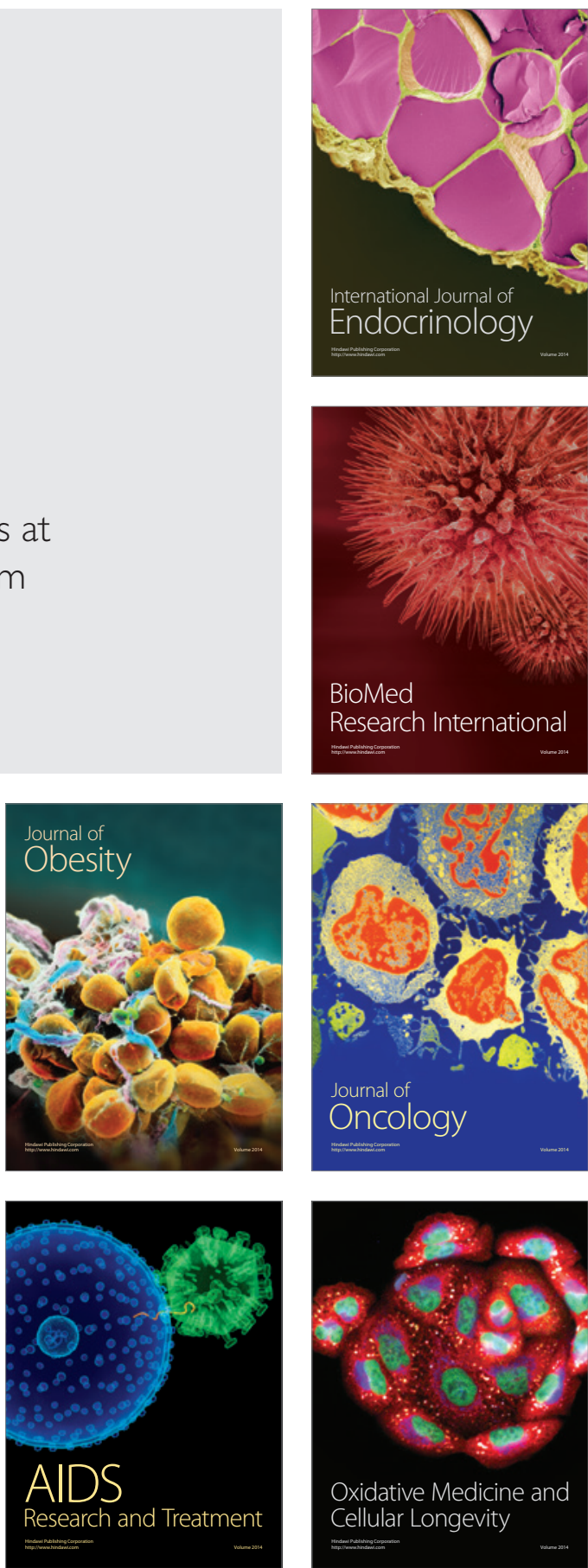